\title{
PRINCIPAIS DESAFIOS DO DESEMPENHO TÉRMICO DAS EDIFICAÇÕES NO BRASIL: UMA REVISÃO
}

\author{
MARTINS, PAULA DANIELA \\ Engenheira Civil \\ Universidade Federal de Ouro Preto \\ Minas Gerais; Brasil \\ paula.daniela@aluno.ufop.edu.br
}

\author{
PEREIRA E ALVARENGA, MAJDA \\ Graduanda em Engenharia Civil \\ Universidade Federal de Ouro Preto \\ Minas Gerais; Brasil \\ majda.alvarenga@aluno.ufop.edu.br
}

\author{
PEREIRA SANTANA, VANESSA \\ Mestranda em Engenharia Civil \\ Universidade Federal de Ouro Preto \\ Minas Gerais; Brasil \\ vanessa.pesantana@gmail.com
}

\author{
Engenheiro Civil, D. Sc. \\ Universidade Federal de Ouro Preto \\ Minas Gerais; Brasil \\ guilhermebrigolini@ufop.edu.br
}

BRIGOLINI SILVA, GUILHERME JORGE

\author{
CASTRO MENDES, JÚLIA \\ Engenheira Civil, D. Sc. \\ Universidade Federal de Ouro Preto \\ Minas Gerais; Brasil \\ julia.mendes@ufop.edu.br
}

\section{RESUMO}

O desempenho térmico de uma edificação é um fator que requer atenção, pois quando este não é satisfatório, ocorrem graves consequências de saúde e produtividade aos usuários, além de alto consumo energético da edificação. No Brasil, verifica-se que grande parte das edificações não é concebida com eficiência térmica, ainda que isso interfira no desempenho da construção. Assim, este trabalho consiste em uma revisão bibliográfica dos principais obstáculos para obtenção do bom desempenho térmico e eficiência energética nas edificações brasileiras, a partir da análise de artigos publicados em revistas de alto impacto científico na última década. Os resultados apontam que a inconsistência e falta de atualização das normas brasileiras, a falta de capacitação dos profissionais do setor e a necessidade de um maior investimento inicial são os principais desafios enfrentados para inibir manifestações patológicas associadas ao desempenho térmico nas habitações brasileiras.

Palavras-chave: Desconforto Térmico, Desempenho Térmico, Edificações Brasileiras.

\section{ABSTRACT}

The thermal performance of an edition is a factor that requires attention, because when it is not satisfactory, a pathological condition arises, with serious consequences for health and users. In Brazil it appears that most of the buildings are not designed with thermal efficiency, even though this design flaw interferes with the construction performance. Thus, the present work consists of a literature review of the main obstacles to obtain suitable thermal performance and energy efficiency in Brazilian buildings, from the analysis of papers published in high impact journals in the last decade. The results show that the inconsistency and lack of updating of Brazilian standards the lack of training of professionals in the sector and the need for greater initial investment are the main challenges faced to inhibit the appearance of pathological manifestations associated with thermal performance in Brazilian housing.

Keywords: Thermal Discomfort, Thermal Performance, Brazilian buildings.

\section{INTRODUÇÃO}

As edificações das primeiras civilizações tinham a função principal de proteger os seus usuários de intempéries e por isso o clima local sempre foi o fator determinante na elaboração das construções. Um projeto arquitetônico adaptado ao clima do local construído pode proporcionar um adequado desempenho térmico do ambiente interno tornando-o mais confortável para os usuários. A NBR 15220 (ABNT, 2005) define conforto térmico como sendo a satisfação de um 
usuário no âmbito psíquico e fisiológico com as condições de um determinado ambiente. É um conceito subjetivo que pode variar de indivíduo para indivíduo, mas que tem grande importância para o bem-estar dos ocupantes.

Já o desempenho térmico de uma edificação corresponde à resposta da habitação, em termos de parâmetros climáticos internos, em relação ao clima da área em que se encontra (GONÇALVES, 2004). Um ambiente com desempenho térmico adequado proporcionará a sensação de conforto a seus usuários e deve ser, sempre que possível, energicamente eficiente.

Edifícios energeticamente eficientes devem proporcionar a sensação de conforto térmico com mínima ou nenhuma necessidade equipamentos de resfriamento e aquecimento, uma vez que estes são responsáveis por grande parte do gasto de energia da edificação (GONÇALVES, 2004). . Um ambiente termicamente confortável proporciona aos ocupantes melhor rendimento em atividades intelectuais e físicas, visto que o organismo gasta menos energia para manter a temperatura corporal dentro dos limites toleráveis (LAMBERTS, GHISI, et al., 2010). Enquanto o conforto térmico é uma sensação subjetiva relacionada às características de cada pessoa, o desempenho térmico é um fator objetivo da edificação, definido quantitativamente por normas, que traz prescrições para garantir o conforto térmico à maior parte dos usuários.

A patologia construtiva pode ser associada ao não atendimento ao desempenho desejado por um dado sistema. As edificações devem satisfazer condições mínimas de aspectos de habitabilidade, manutenibilidade e uso, e estes requisitos são normalmente expressos através de critérios estabelecidos por normas técnicas que descrevem também as condições que devem ser atendidas pelos materiais e componentes das edificações (ZUCHETTI, 2015). Dessa forma, infere-se que as edificações que não oferecem um desempenho térmico satsifatório apresentam um quadro patológico. Tais manifestações patológicas resultam em graves consequências de saúde e produtividade aos usuários, além de causar direta influência no consumo de energia, uma vez que os ocupantes tendem a tomar medidas para torná-lo confortável, como uso equipamentos de resfriamento e aquecimento.

No Brasil, as principais normativas que orientam sobre o desempenho térmico das edificações são a NBR 15220 (ABNT, 2005) e a NBR 15575 (ABNT, 2013). A NBR 15220 (ABNT, 2005), intitulada "Desempenho térmico de edificações", define as variáveis que devem ser consideradas para obter melhorias no desempenho térmico das edificações. Esta norma é dividida em 5 seções onde além de recomendações construtivas de acordo com as Zonas Bioclimáticas Brasileiras, apresenta, também, informações sobre as grandezas dos elementos e componentes da edificação que influenciam no comportamento térmico da habitação.

A NBR 15575 "Edificações Habitacionais - Desempenho" (2013) traz os requisitos mínimos de desempenho, segurança e vida útil para os sistemas das habitações. A norma é dividida em 6 partes e é organizada por aspectos de desempenho, como segurança estrutural, segurança contra incêndio, durabilidade, desempenho térmico e acústico (SOUZA, KERN e TUTIKIAN, 2018). A norma de desempenho, como é conhecida, foi publicada em 2013 e considerada como um importante marco tecnológico da indústria construtiva no Brasil. Ela estabelece os requisitos mínimos de qualidade que a edificação deve apresentar após sua construção. Assim, como o foco é voltado para o usuário, as suas necessidades são consideradas duarante a vida útil da edificação (AMARAL, MAIA, et al.).

Mesmo com a existência de normas que preconizam o adequado desempenho térmico das construções, muitas vezes surge a necessidade de readequação e modernização de edificações com o objetivo de preservar o ambiente construído e remover seus aspectos patológicos, aumentar sua vida útil, reduzir o impacto no meio ambiente e principalmente promover melhores condições de uso para seus ocupantes. Esta prática é conhecida por retrofit, que pode ser também definido, resumidamente, como o processo de revitalização de edifícios. De acordo com a Fundação Getúlio Vargas (2017) a economia de energia após um retrofit, dependendo do tipo de empreendimento, pode variar entre $18 \%$ a $39 \%$. Tais números mostram que a prática pode impactar a redução do consumo de energia nos mais variados setores e, assim, garantir edifícios mais sustentáveis e que atenda às necessidades dos ocupantes de forma eficiente. Além disso, o investimento no retrofit foca nas novas demandas de uso dos usuários e melhora as características estéticas e o desempenho dos sistemas, que além de agregar maior valor de mercado à edificação, promove a saúde e bem estar do ocupante (TÉCHNE, 2016).

Contudo, observa-se que grande parte das habitações brasileiras é construída sem um sistema de aquecimento ou resfriamento integrado, fazendo com que um grande número de famílias busque melhorar o desempenho térmico de seu ambiente a partir do condicionamento artificial do ambiente, como medida paliativa (PAULSEN e SPOSTO, 2013). Aliado a isso e, diante do crescimento da urbanização em conjunto com o aumento populacional e das mudanças 
climáticas, o consumo de energia elétrica tem-se elevado em todos os setores (AGÊNCIA BRASIL, 2019). Os setores residencial e comercial corresponderam, em 2018, a 65\% do total de energia elétrica consumida no país (EPE, 2018). Uma das contribuições para a diminuição do consumo é projetar e executar edificações naturalmente mais eficientes sob a ótica do desempenho térmico (LAMBERTS, DUTRA e PEREIRA, 2014). Isto reduziria largamente a necessidade de equipamentos para aquecimento e resfriamento, os quais são responsáveis por grande parte do gasto de energia em uma residência (LAMBERTS, GHISI, et al., 2010). Tais fatos são claras evidências da não satisfatoriedade do desempenho térmico apresentado por grande parte das habitações brasileiras e da necessidade de intervenções nas edificações após o período de construção.

Considerando o exposto, o presente estudo propôs uma revisão bibliográfica, de estudos de casos e discussões a respeito do desempenho térmico das habitações brasileiras no cenário atual. A partir da análise de artigos publicados em revistas de alto impacto, propõe-se identificar os principais desafios para construção de edificações energeticamente eficientes e termicamente confortáveis no Brasil.

\section{METODOLOGIA}

Para a realização deste trabalho foram analisados onze artigos científicos e publicações, conforme apresentados na Tabela 1, os quais serviram de embasamento teórico na investigação dos principais desafios encontrados para se projetar e construir edificações termicamente eficientes.

Foram selecionados artigos publicados em revistas internacionais, com grande impacto na comunidade acadêmica e peso científico. Além disso, foram escolhidos preferencialmente trabalhos realizados na última década sobre o desempenho térmico no Brasil de forma a estabelecer discussões atuais. Algumas publicações não específicas do Brasil foram analisadas para fins comparativos.

Tabela 1 - Artigos utilizados para avaliar os desafios do desempenho térmico nas edificações do Brasil

\begin{tabular}{|c|c|c|c|}
\hline Autor & Ano & Título & Revista \\
\hline Huang et al. & 2018 & $\begin{array}{l}\text { Post-evaluation of energy consumption of the } \\
\text { green retrofit building }\end{array}$ & Energy Procedia \\
\hline El-Darwish e Gomaa & 2017 & $\begin{array}{c}\text { Retrofitting strategy for building envelopes to } \\
\text { achieve efficiency }\end{array}$ & $\begin{array}{c}\text { Alexandria Engineering } \\
\text { Journal } \\
\end{array}$ \\
\hline Felix e Elsamahy & 2017 & $\begin{array}{l}\text { The efficiency of using different outer wall } \\
\text { construction materials to achieve thermal comfort } \\
\text { in various climatic zones }\end{array}$ & Energy Procedia \\
\hline Oliveira, Souza e Silva & 2017 & $\begin{array}{c}\text { Issues to be improved on the Thermal } \\
\text { Performance Standards for Sustainable Buildings } \\
\text { consolidation: an overview of Brazil }\end{array}$ & Energy procedia \\
\hline $\begin{array}{l}\text { Moreno, Morais e } \\
\text { Souza } \\
\end{array}$ & 2016 & $\begin{array}{c}\text { Thermal Performance of Social Housing - A } \\
\text { study based on Brazilian Regulations }\end{array}$ & Energy Procedia \\
\hline Wilkinson et al. & 2016 & $\begin{array}{c}\text { Evaluating the thermal performance of retrofitted } \\
\text { lightweight green roofs and walls in Sydney and } \\
\text { Rio de Janeiro }\end{array}$ & Procedia Engeneering \\
\hline Oliveira et al. & 2015 & $\begin{array}{l}\text { Concrete walls thermal performance analysis by } \\
\text { Brazilian Standards }\end{array}$ & Energy Procedia \\
\hline $\begin{array}{l}\text { Triana, Lamberts e } \\
\text { Sassi }\end{array}$ & 2015 & $\begin{array}{l}\text { Characterization of representative building } \\
\text { typologies for social housing projects in Brazil } \\
\text { and its energy performance. }\end{array}$ & Energy Policy \\
\hline Paulsen e Sposto & 2013 & $\begin{array}{c}\text { A life cycle energy analysis of social housing in } \\
\text { Brazil: Case study for the program "MY HOUSE } \\
\text { MY LIFE". }\end{array}$ & Energy and Buildings \\
\hline $\begin{array}{c}\text { Pacheco, Ordóñez e } \\
\text { Martínez }\end{array}$ & 2012 & Energy efficient design of building: A review & $\begin{array}{c}\text { Renewable and Sustainable } \\
\text { Energy Reviews }\end{array}$ \\
\hline Bodach e Hamhaber & 2010 & $\begin{array}{c}\text { Energy efficiency in social housing: } \\
\text { Opportunities and barriers from a case study in } \\
\text { Brazil }\end{array}$ & Energy Policy \\
\hline
\end{tabular}




\section{RESULTADOS}

De acordo com o estudo e análise dos artigos, vários fatores foram apontados como motivadores para não concepção de edificações com o adequado desempenho térmico nas habitações brasileiras. Dentre os agentes mais citados estão a deficiência de normas e fiscalização, a baixa capacitação dos profissionais da área, a necessidade de maior investimento inicial e a dificuldade de realização de intervenções futuras. A Tabela 2 apresenta, de forma resumida, as principais barreiras mencionadas por cada autor, bem como uma breve discussão a respeito do desafio citado.

Tabela 2 - Análise dos principais desafios citados nos artigos para se alcançar um bom desempenho térmico nas edificações

\begin{tabular}{|c|c|c|}
\hline Desafio & Referência & Discussão \\
\hline \multirow{3}{*}{ Normas } & $\begin{array}{l}\text { (OLIVEIRA, SOUZA } \\
\text { SILVA, 2017) }\end{array}$ & $\begin{array}{l}\text { Segundo o estudo, as normas NBR } 15220 \text { e NBR } 15575 \text { apresentam } \\
\text { discrepâncias entre alguns valores sobre as características do sistema } \\
\text { de fechamento. Isto dificulta que as normas sejam seguidas pelos } \\
\text { projetistas e construtores. }\end{array}$ \\
\hline & $\begin{array}{l}\text { (OLIVEIRA, SOUZA, et } \\
\text { al., 2015) }\end{array}$ & \multirow{2}{*}{$\begin{array}{l}\text { Os autores salientam a necessidade de revisão de ambas as normas, } \\
\text { pois a NBR } 15220 \text { apresenta valores mínimos insuficientes para } \\
\text { adequado desempenho térmico em construções pertencentes a } \\
\text { algumas zonas bioclimáticas e a NBR } 15575 \text { precisa de adequação } \\
\text { sobre as orientações no método de simulação computacional. }\end{array}$} \\
\hline & $\begin{array}{l}\text { (TRIANA, LAMBERTS e } \\
\text { SASSI, 2015) }\end{array}$ & \\
\hline \multirow{5}{*}{ Projeto } & $\begin{array}{l}\text { (FELIX e ELSAMAHY, } \\
\text { 2017) }\end{array}$ & $\begin{array}{l}\text { É necessário especificar detalhadamente os materiais que compõem o } \\
\text { sistema de fechamento, visto que é o elemento que regula o fluxo de } \\
\text { calor. Devem-se ser considerados, principalmente, dois quesitos: as } \\
\text { propriedades termofísicas dos elementos e a zona bioclimática em } \\
\text { que se localiza a edificação. }\end{array}$ \\
\hline & $\begin{array}{l}\text { (MORENO, MORAIS e } \\
\text { SOUZA, 2016) }\end{array}$ & $\begin{array}{l}\text { De acordo com os autores, as habitações brasileiras, principalmente } \\
\text { aquelas construídas por programas de financiamento sociais, não } \\
\text { foram projetadas de acordo com a zona bioclimática, nem com } \\
\text { materiais que garantiriam maior conforto térmico para os moradores. }\end{array}$ \\
\hline & $\begin{array}{l}\text { (PAULSEN e SPOSTO, } \\
2013 \text { ) }\end{array}$ & $\begin{array}{l}\text { Necessidade de especificar materiais com menor energia } \\
\text { incorporada, com maior qualidade e durabilidade. Deve-se levar em } \\
\text { consideração a aplicabilidade diante dos fatores: exposição da } \\
\text { edificação, clima, temperatura, umidade, entre outros. }\end{array}$ \\
\hline & $\begin{array}{l}\text { (TRIANA, LAMBERTS e } \\
\text { SASSI, 2015) }\end{array}$ & $\begin{array}{l}\text { Na maioria das vezes os projetos não são concebidos de acordo com } \\
\text { a zona bioclimática local. Isto ocorre, pois, as técnicas construtivas e } \\
\text { design das edificações seguem, normalmente, o mesmo padrão em } \\
\text { todo o país. }\end{array}$ \\
\hline & $\begin{array}{l}\text { (PACHECO, ORDÓÑEZ e } \\
\text { MARTÍNEZ, 2012) }\end{array}$ & $\begin{array}{l}\text { Normalmente não se considera a envoltória como um sistema } \\
\text { regulador de calor, nem as propriedades termodinâmicas durante a } \\
\text { elaboração do projeto. Raramente são considerados o formato e a } \\
\text { orientação do edifício para se garantir conforto térmico aos usuários. }\end{array}$ \\
\hline Fiscalização & $\begin{array}{l}\text { (BODACH E HAMHABER, } \\
\text { 2010) }\end{array}$ & $\begin{array}{l}\text { Os autores salientam que os desafios vão além da uniformização e } \\
\text { atualização das normas. Existe a necessidade de garantir fiscalização } \\
\text { e cumprimento destas normas, já que a informalidade chega a } 60 \% \\
\text { no setor da construção brasileira. Assim, a falta de fiscalização não } \\
\text { incentiva a busca por conhecimento e cumprimento das normas por } \\
\text { parte dos profissionais. }\end{array}$ \\
\hline \multirow{2}{*}{$\begin{array}{l}\text { Capacitação e } \\
\text { Conscientização }\end{array}$} & \multirow{2}{*}{$\begin{array}{l}\text { (BODACH E HAMHABER, } \\
\text { 2010) }\end{array}$} & $\begin{array}{l}\text { Normalmente, o interesse das construtoras se resume à fase de } \\
\text { construção, principalmente para habitações sociais. Assim, o } \\
\text { consumo e, por consequência, os custos de energia elétrica são de } \\
\text { responsabilidade apenas do morador. }\end{array}$ \\
\hline & & $\begin{array}{l}\text { Os projetistas, assim como os profissionais da construção, têm pouco } \\
\text { ou nenhum conhecimento sobre desempenho térmico ou eficiência } \\
\text { energética. }\end{array}$ \\
\hline
\end{tabular}




\begin{tabular}{|c|c|c|}
\hline Desafio & Referência & Discussão \\
\hline \multirow{4}{*}{ Investimento } & $\begin{array}{l}\text { (TRIANA, LAMBERTS e } \\
\text { SASSI, 2015) }\end{array}$ & \multirow{2}{*}{$\begin{array}{l}\text { Os autores avaliaram que o orçamento para a construção é limitado } \\
\text { para a maioria da população. Isto resulta em habitações de baixa } \\
\text { qualidade e baixo desempenho térmico, pois, principalmente para a } \\
\text { classe de baixa renda, prioriza-se os custos de curto prazo, sem } \\
\text { considerar os benefícios a longo prazo de maiores investimentos. }\end{array}$} \\
\hline & $\begin{array}{l}\text { (BODACH e HAMHABER, } \\
\text { 2010) }\end{array}$ & \\
\hline & $\begin{array}{l}\text { (PACHECO, ORDÓÑEZ e } \\
\text { MARTÍNEZ, 2012) }\end{array}$ & $\begin{array}{l}\text { O estudo mostra que geralmente, o usuário se preocupa em intervir } \\
\text { no edifício para melhorar o desempenho térmico e a eficiência } \\
\text { energética durante a fase de uso. No entanto, quanto mais tarde } \\
\text { acontece a implementação de soluções, mais caro é o processo. }\end{array}$ \\
\hline & $\begin{array}{l}\text { (BODACH e HAMHABER, } \\
\text { 2010) }\end{array}$ & $\begin{array}{l}\text { Para instituições de financiamento a política principal é construir o } \\
\text { maior número de edificações com o menor investimento, visando } \\
\text { resolver apenas o problema do déficit de habitações. }\end{array}$ \\
\hline \multirow[b]{3}{*}{ Retrofit } & $\begin{array}{l}\text { (HUANG, GE e SHEN, } \\
\text { 2018) }\end{array}$ & $\begin{array}{l}\text { As estratégias adotadas precisam estar de acordo com a zona } \\
\text { climática local. Além disso, o autor salienta que os retrofits são } \\
\text { menos eficazes do que as intervenções realizadas ainda durante a fase } \\
\text { de execução do projeto. }\end{array}$ \\
\hline & $\begin{array}{l}\text { (EL-DARWISH e GOMAA, } \\
\text { 2017) }\end{array}$ & $\begin{array}{l}\text { Os autores citam a necessidade de encontrar estratégias viáveis que } \\
\text { se aplicam aos edifícios já construídos para melhorar o desempenho } \\
\text { térmico, como barreiras térmicas, insolação e sombreamento. }\end{array}$ \\
\hline & $\begin{array}{l}\text { (WILKINSON, FEITOSA, } \\
\text { et al., 2017) }\end{array}$ & $\begin{array}{l}\text { Segundo o estudo, estratégias, como telhados e paredes verdes, } \\
\text { podem não ser soluções sempre viáveis devido à região em que o } \\
\text { edifício está localizado, área útil para intervenção, capacidade de } \\
\text { suporte da estrutura e, em alguns casos, o retorno pode não } \\
\text { compensar o valor investido. Os autores avaliaram que o melhor } \\
\text { desempenho desta estratégia acontece em regiões de clima quente e } \\
\text { seco. Portanto, as diferenças entre o tipo de construção, clima e local } \\
\text { do edifício são fundamentais para determinar as intervenções de } \\
\text { retrofit. }\end{array}$ \\
\hline
\end{tabular}

Alguns autores citam que a dificuldade de construção de edificícios termicamente eficientes no Brasil está associada a alguns aspectos das normas técnicas existentes. Segundo Triana et al. (2015) e Oliveira et al. (2017) as normas brasileiras apresentaram falhas quanto aos valores mínimos estabelecidos para assegurar conforto térmico aos usuários. Tal fato prejudica a concepcção de projetos eficientes, o que afeta na prática os requisitos de desempenho. Os mesmos autores apontam a necessidade revisão das normas, uma vez que a NBR 15220 apresenta valores mínimos insuficientes para adequado desempenho térmico em construções pertencentes a algumas zonas bioclimáticas e a NBR 15575 precisa de adequação sobre as orientações no método de simulação computacional.

Apesar de representar um marco tecnológico que trouxe novos conceitos para a avaliação de edificações e concepção de sistemas inovadores ao Brasil, a Norma de Desempenho ainda apresenta falhas podem ser explicadas pela falta de atualização da mesma. A NBR 15575 (ABNT, 2013) não passa por atualizações há mais de 6 anos, enquanto a NBR 15220 (ABNT, 2005), há 15. Em comparação, a norma que visa ao maior desempenho energético e foca na performace do sistema de fechamento da edificação no Reino Unido, The Building Regulation - Part L - Conservation of Fuel and Power (2010), sofreu alterações nos anos de 1976, 1985, 1990, 1995, 2002, 2006 e 2013. Além disso, há emendas que também são adicionadas quase anualmente, com a última em 2018 (KINGSCOTT, 2018). A revisão contínua aprimora as técnicas já utilizadas, atualiza os valores limites e permite incluir novas abordagens construtivas.

Além das falhas relativas aos índices mínimos requisitados, as normas brasileiras abordam apenas estratégias para edificações novas, ainda na fase de projeto. Assim, a ausência de orientações para edifícios já construídos pode ser considerada mais uma barreira para o alcance de melhor desempenho térmico das edificações brasileiras. Comparativamente, em outros países como no Reino Unido, The Building Regulation - Part L - (2010) estabelece regulamentos para habitações novas e existentes e para construções novas e existentes que não sejam habitações, mostrando uma maior preocupação em abranger diferentes possibilidades (KINGSCOTT, 2018).

Diante da definciência nas diretrizes e da dificuldade de adequação para diferentes tipos de obras, a tendência é que os projetistas não apoiem suas concepções nestas normas. Além da falta de revisões, outro fator que intensifica o não 
cumprimento é o custo para aquisição das normas - para a obtenção das normas NBR 15220 (ABNT, 2005) e NBR 15575 (ABNT, 2013) completas o preço pago seria de R\$1364,70 (ABNT CATÁLOGO, 2019). Assim, o custo de aquisição se mostra como uma barreira para que os profissionais tenham acesso ao material e pratiquem as diretrizes. Já no Reino Unido, as normas são disponibilizadas gratuitamente no site do governo britânico. O fácil acesso incentiva a utilização e cumprimento das mesmas.

Além das questões associadas às normas, a informalidade na cadeia produtiva da construção civil brasileira, que chega a $60 \%$ das atividades do setor, é outro agravante para o baixo desempenho das edificações (BODACH e HAMHABER, 2010). O setor da construção civil conta com poucos projetos e construções pensadas para a eficiência térmica e isto é decorrente do grande número de habitações construídas sem o projeto e sem acompanhamento de qualquer profissional, as autoconstruções. Ainda hoje é persistente a ideia errônea de que engenheiros e arquitetos são profissionais dispensáveis, e que só elevam o valor da obra (NOVAES, 2019). Uma pesquisa realizada pelo Conselho de Arquitetura e Urbanismo (CAU/BR) e pelo Instituto de Pesquisa DATAFOLHA, em 2015, mostrou que 85\% das reformas e construções realizadas pelos entrevistados ocorreram sem o acompanhamento de um profissional especializado (CAU/BR e DATAFOLHA, 2015). Bodach e Hamhaber (2010), em seu estudo, enfatizaram a necessidade de maior fiscalização no setor para garantir o acompanhamento das construções e o cumprimento das normas e diretrizes uma vez que a falta de fiscalização não incentiva a busca por conhecimento e cumprimento das normas por parte dos profissionais.

Somado às normas e fiscalização insatisfatórias, outro desafio a ser superado é a pouca ou nenhuma capacitação dos profissionais na área de desempenho térmico. Disciplinas sobre conforto térmico e eficiência energética têm pouca inserção nas universidades brasileiras, que formam profissionais com pouco conhecimento sobre o tema. Normalmente estes conteúdos são opcionais, teóricos e, ainda que os estudantes tenham contato, o conhecimento é raramente aplicado na prática, dificultando a sua aplicação no mercado de trabalho (BODACH e HAMHABER, 2010).

O baixo incentivo na difusão de conhecimento sobre conforto implica na concepção de projetos inadequados sob o aspecto do desempenho térmico e na repetição do processo construtivo ineficaz já existente. Comumente, a manifestação patológica relativa ao desempenho térmico é relativizada ainda durante a etapa de projeto. Profissionais da construção consideram comum a necessidade de aparelhos para aquecimento e resfriamento do ambiente e raramente avaliam as condições de orientação do edifício, propriedades termofísicas dos materiais e estratégias passivas para garantir o conforto térmico para os ocupantes. Muitos autores citam o desenvolvimento do projeto sem considerar o ambiente onde a construção está inserida (MORENO, MORAIS e SOUZA, 2016; TRIANA, LAMBERTS e SASSI, 2015; PACHECO, ORDÓÑEZ e MARTÍNEZ, 2012).

Segundo Triana et al. (2015), na maioria das vezes os projetos não são concebidos de acordo com a zona bioclimática local. Isto ocorre, pois, mesmo o Brasil possuindo clima bastante variado em todo seu território devido à sua grande extensão, as técnicas construtivas e design das edificações seguem, normalmente, o mesmo padrão em todo o país. Segundo Pacheco et al. (2012), raramente são considerados o formato e a orientação do edifício para se garantir conforto térmico aos usuários. Moreno et al. (2016) além de apontar que as habitações brasileiras, principalmente aquelas construídas por programas de financiamento sociais, não foram projetadas de acordo com a zona bioclimática, alega que não são utilizados materiais que garantiriam maior conforto térmico para os moradores.

Para melhor desempenho térmico da habitação é necessário especificar detalhadamente os materiais que a compõem, principalmente o sistema de vedação, visto que é o elemento que regula o fluxo de calor (FELIX e ELSAMAHY, 2017). Entretanto, durante a etapa de execução da obra, normalmente, não é comum a solicitação de informação sobre as propriedades térmicas dos materiais para os fabricantes ou ensaios para avaliação destas. Assim, devido à baixa demanda, os fabricantes não são estimulados a pensar em inovações dos materiais ou do processo de construção. $\mathrm{O}$ setor da construção civil no Brasil ainda é considerado artesanal, onde a maioria dos materiais é preparada in loco, com pouco ou nenhum controle tecnológico. Paulsen e Sposto (2013) apontam para a necessidade de especificar materiais com menor energia incorporada, com maior qualidade e durabilidade. Assim, deve-se ser considerada a aplicabilidade diante dos fatores: exposição da edificação, clima, temperatura, umidade, entre outros. Todas estas condições influenciam diretamente no comportamento térmico das edificações.

Outro fator que influencia negativamente na concepção de habitações com bom desempenho térmico é a prática de buscar o mínimo investimento possível para a execução da obra. O investimento inicial é, na maioria das vezes, reduzido mesmo que na fase de uso o retorno financeiro pudesse ser compensado pela economia de energia elétrica (BODACH e HAMHABER, 2010). Isto pode ser evidenciado principalmente nas habitações sociais, cujo investimento 
governamental busca gerar o maior número de habitações possível para suprir a demanda habitacional do país (MORENO, MORAIS e SOUZA, 2016). Similarmente, a parcela mais pobre da população apresenta orçamento limitado para investir em inovações tecnológicas para maior eficiência energética da edificação (TRIANA, LAMBERTS e SASSI, 2015).

É fundamental observar ainda que tais desafios poderiam ser solucionados na etapa de projeto. Pacheco, Ordóñez e Martínez (2012) mostraram em seu estudo que quanto antes as intervenções forem estudadas e implementadas, menores serão seus custos. El-Darwish e Gomaa (2017) citam, então, a necessidade de encontrar estratégias viáveis que se aplicam aos edifícios já construídos para melhorar seu desempenho térmico, como barreiras térmicas, insolação e sombreamento.

Huang, Ge e Shen (2018) mostraram que a economia de energia em edifícios que já foram projetados energicamente eficientes é de $30 \%$ a $50 \%$ maior do que aqueles que passaram por retrofit. Mas, ainda que o retorno financeiro seja menos eficiente do que as soluções pensadas durante a concepção do projeto, o processo de retrofit apresenta bons resultados para aumento do desempenho térmico. Contudo, é importante mencionar que o retrofit adequadamente realizado consiste em intervenções pensadas especificamente para o edifício e região em questão. Ou seja, as soluções não devem ser padronizadas para serem utilizadas da mesma forma em todas as situações. Wilkinson, Feitosa, et al. (2017) citam que um exemplo é o uso indiscriminado de telhados e paredes verdes que, como apresentam, dependem da área útil da edificação, tipo de vegetação local e do suporte da estrutura. Assim, as diferenças entre o tipo de construção, clima e local do edifício são fundamentais para determinar as intervenções de retrofit.

Todas estas condições citadas demonstram que edificações com baixo desempenho térmico podem provocar duas consequências: os usuários convivem com o desconforto térmico e têm sua produtividade e bem-estar comprometidos ou fazem uso de equipamentos de aquecimento e resfriamento para melhorar a sensação de conforto no ambiente. Esta prática eleva tanto as despesas com energia elétrica para o consumidor, quanto em investimentos governamentais para suprir a maior demanda.

\section{CONCLUSÃO}

As edificações devem satisfazer condições mínimas de habitabilidade. Quando estes requisitos de desempenho não são atendidos, impedindo ou dificultando a plena utilização do espaço construído, induz-se que há uma manifestação patológica construtiva. Um ambiente desconfortável termicamente provoca mal-estar e pode comprometer a produtividade e a saúde de seus ocupantes. Diante desse cenário os usuários normalmente recorrem a sistemas de resfriamento e aquecimento como medida paliativa para as deficiências no desempenho térmico dos edifícios.

Dessa forma, o presente trabalho buscou identificar as principais barreiras que dificultam o desenvolvimento de empreendimentos termicamente competentes no Brasil, segundo as informações de artigos publicados em revistas internacionais de alto impacto na última década. Entre os principais motivos, pode-se citar que a maioria das habitações brasileiras não conta com um projeto que leva em consideração as condições climáticas da região, o tipo de sistema de fechamento e os materiais mais adequados para sua construção. Isto é resultado da inconsistência e falta de atualização das normas que tratam do tema, pela falta de conhecimento dos projetistas sobre conforto e desempenho térmico e, também, pela falta de fiscalização para o cumprimento das normas.

Além disso, muitas vezes as construções brasileiras são completadas sem projeto ou sem o acompanhamento por profissionais qualificados. A informalidade e pouca qualificação da mão de obra compromete a qualidade do produto final. O orçamento limitado de grande parte da população também impede que sejam realizados investimentos em projetos adequados, materiais de qualidade e inovação tecnológica para assegurar edificações termicamente eficientes.

Para que os projetos dos edifícios brasileiros sejam adequados é necessário que os profissionais estejam capacitados sobre os temas de desempenho térmico e eficiência energética. Além disso, sob responsabilidade da Associação Brasileira de Normas Técnicas (ABNT), as normas precisam ser atualizadas constantemente e trazer novas abordagens construtivas, tanto para edificações novas quanto para as existentes. Durante a etapa de construção, é imprescindível que os órgãos responsáveis, como o governo municipal, estadual e federal e conselhos de arquitetura e engenharia fiscalizem as obras para garantir que estas estejam sendo acompanhadas pelos profissionais apropriados. Cabe também a estes órgãos fiscalizar as construtoras para avaliar as condições de projeto e obra. 
Finalmente, é preciso criar incentivos para mudar a forma de se projetar e construir no Brasil. Não é suficiente, apenas, que os problemas do déficit habitacional e aumento do consumo de energia sejam solucionados, mas também devem ser melhoradas a qualidade e habitabilidade das construções. A população deve ser conscientizada da necessidade e importancia da contratação dos profissionais devidamente capacitados e estes precisam levar em consideração estratégias para alcançar maior desempenho térmico nos edifícios brasileiros.

\section{AGRADECIMENTOS}

O presente trabalho foi realizado com apoio da Coordenação de Aperfeiçoamento de Pessoal de Nível Superior - Brasil (CAPES) - Código de Financiamento 001. Os autores também agradecem à FAPEMIG, CNPq e UFOP pelo apoio para a realização e apresentação dessa pesquisa. Somos gratos ainda pela infraestrutura e colaboração do Grupo de Pesquisa em Resíduos Sólidos - RECICLOS - CNPq.

\section{REFERÊNCIAS}

ASSOCIAÇÃO BRASILEIRA DE NORMAS TÉCNICAS. NBR15220: Desempenho Térmico de Edificações. Rio de Janeiro. 2005.

ASSOCIAÇÃO BRASILEIRA DE NORMAS TÉCNICAS. NBR 15575: Edificações Habitacionais - Desempenho. Rio de Janeiro. 2013.

AMARAL, C. S. N.; MAIA, F. N.; d'AVILA, J. F. N; VITALE, O. Norma de Desempenho: um marco regulatório na construção civil, 2019. Disponivel em: <http://precisao.eng.br/public/manual-nd.pdf〉. Acesso em: 10 dez. 2019.

BODACH, S.; HAMHABER, J. Energy efficiency in social housing: Opportunities and barriers from a case study in Brazil. Energy Policy, p. 7898-7910, Stembro 2010.

CAU/BR, C. D. A. E. U.; DATAFOlHA. Pesquisa CAU/BR DATAFOLHA. Conselho de Arquitetura e Urbanismo do Brasil, 2015. Disponivel em: <http://www.caubr.gov.br/pesquisa2015/>. Acesso em: 21 Abril 2019.

EL-DARWISH, I.; GOMAA, M. Retrofitting strategy for building envelopes to achieve energy efficiency. Alexandria Engineering Journal, p. 579-589, 2017.

EPE, E. D. P. E. Consumo de Energia Elétrica. Empresa de Pesquisa Energética, 2018. Disponivel em: <http://epe.gov.br/pt/areas-de-atuacao/energia-eletrica/consumo-de-energia-el\%C3\%A9trica>. Acesso em: 12 Maio 2019.

FELIX, M.; ELSAMAHY, E. The Efficiency of Using Different Outer Walls Construction Materials to Achieve Thermal Comfort in Varios Climatic Zones. Energy Procedia, p. 321-331, 2017.

FGV. Edificações Sustentáveis e Eficiência Energética. Fundação Getúlio Vargas. p. 52. 2017.

GONÇALVES, H. Ambiente construído: clima urbano, utilização racional de energia nos edifícios da cidade de Lisboa. Lisboa: INETI, 2004.

HUANG, Z.; GE, J.; SHEN, J. Post-evaluation of energy consumption of the green retrofit building. Energy Procedia, p. 3608-3613, 2018.

KINGSCOTT, T. C. C. Comparative Analysis of Thermal Performance Towards for Buildings Between Brazil and the United Kingdom. Universidade Federal de Ouro Preto. Ouro Preto , p. 77. 2018.

LAMBERTS, R.; GHISH, E.; PEREIRA, C.D.; BATISTA, J. O. Casa Eficiente: Bioclimatologia e Desempenho Térmico. Florianópolis: UFSC/LabEEE, 2010.

LAMBERTS, R.; DUTRA, L.; PEREIRA, F. O. R. Eficiência Energética na Arquitetura. Rio de Janeiro: ELETROBRÁS, 2014. 
MOREnO, A. C. R.; MORAIS, I. S. D.; SOUZA, R. V. G. D. Thermal Performance of Social Housing - A Study Based on Brazilian Regulations. Energy Procedia, p. 111-120, 2016.

NOVAES, L. A. Autoconstrução no Brasil - Panorama Geral e Estudo de Caso. Universidade Federal de Ouro Preto. Ouro Preto , p. 51. 2019.

OLIVEIRA, R. D.; SOUZA, R. V. G. D.; SILVA, R. M. D. Issues to be improved on the Thermal Performance Standards for Sustainable Buildings consolidations: an overview of Brazil. Energy Procedia, p. p. 71-80, 2017.

PACHECO, R.; ORDÓÑEZ, J.; MARTÍNEZ, G. Energy efficient design building: A review. Renewable and Sustainable Energy Reviews, p. 3559-3573, 2012.

PAULSEN, J. S.; SPOSTO, R. M. A life cycle energy analysis of social housing in Brazil: Case study for the program "My House My Life". Energy and Buildings, p. 95-102, 2013.

SOUZA, J. L. P. D.; KERN, A. P.; TUTIKIAN, B. F. Análise Quantiqualitaitva da Norma de Desempenho (NBR 15575/2013) e Principais Desafios de Implantação do Nível Superior em Edificação Residencial de Multipavimentos. Gestão \& Tecnologia de Projetos, São Carlos, v. 13, p. 127-144, Fevereiro 2018. ISSN 1.

TÉCHNE. Retrofit: quando é vantajoso requalificar um modernizar uma edificação? São Paulo: Pini, 2016.

TRIANA, M. A.; LAMBERTS, R.; SASSI, P. Characterisation of representative building typologies for social housing projects in Brazil and its energy performance. Energy Policy, p. 524-541, Agosto 2015.

WILKINSON, S. et al. Evaluating the Thermal Performance of Retrofitted Lightweight Green Roofd and Walls in Sydney and Rio de Janeiro. Procedia Engineering, p. 231-240, 2017.

ZUCHETTI, P. A. B. Patologias da construção: investigação patológica em edifício corporativo de administração pública no Vale do Taquari. Centro Universitário UNIVATES. Lajeado. 2015. 